\title{
The Application of Thematic Teaching Method on the Course "Outline of Modern Chinese History”
}

\author{
Li Zhisong \\ The School of Marxism, Northwest University, Xi'an, Shaanxi, China
}

Keywords: Modern Chinese History; Thematic Teaching method

\begin{abstract}
Outline of Modern Chinese History" course has a lot of teaching contents in a relatively limited teaching loads. The thematic teaching method can effectively solve this issue. In order to successfully apply the thematic teaching methods, professors should perfect their teaching contents as well as their teaching methodology.
\end{abstract}

\section{The Problems Existing in the Course Teaching}

"Outline of Modern Chinese History" course was the Marxist ideological and political theory course. It was based on the document "On Further Improve and Perfect the theological and political college students' education” issued by CPC Central Committee and the State Council and document "On Further Improve and Intensify Ideological and Political Course in the Higher Learning Institute and Colleges" and "Implementation Plan" issued by CPC Publicity Department and Ministry Education of the People's Republic of China. "Outline of Modern Chinese History" course, as one of the crucial Marxist course, it mainly focused on anti-aggression fight after the opium war, gradual fighting for the national independence, overthrowing the reactionary puppet rule, the realization of the revolution, the explorations of the development road by Chinese people, the pursuit of the social progress, and the work on modern socialist path with Chinese character. The course expounded the Chinese social and reformist development and summarized the historical and progressive law by helping students to know Chinese modern history and national conditions, understand why Chinese people choose Marxism, Communist Party, socialist path, and reforming and opening policy on its history process with inheritance and promotion of excellent Chinese tradition, and further carrying on the socialist road with Chinese characteristics, with the improvements of students' Marxist standpoint, viewpoint and the ability of analyzing and solving the problems.

"Outline of Modern Chinese History" course, the actual medium teaching text, carried on the heavy assignments with the refreshing textbook arrangements. The arguments were in the history, from the history and within the history. The beginning, middle and ending parts in the textbook design clearly divided the whole content into three parts with many chapters. The whole timeline in the modern Chinese history was well marked and detailed historical periods was clearly depicted in the textbook. The textbook had "demonstration CDs" for some important content with reference. In general, the good quality of the contents with advanced pedagogical approach and well-organized design of "Outline of Modern Chinese History" was a successful and standard textbook. However, this textbook had some problems: how to avoid the same contents repeated in high school history book; how to deepen the teaching contents in "Outline of Modern Chinese History" course; how to state Mao Zedong's thoughts and Chinese Special Socialist Theory taught in "Overview of Mao Zedong" course. As a professor, he should flexibly plan his curriculum based on the textbook rather than completely relied on it. So, "Outline of Modern Chinese History" course was neither the simple further explanation of high school textbook, nor the background preparation for "Introduction to Maoism and Chinese-featured Socialism Ideology" course. It is an independent, comprehensive, and scientific theoretical system. If the lecturers only focused on the textbook and subsidiary readings without any methodological innovation, it was hard to stimulate the study interest of the students and would ended up in low class efficiency. 


\section{Content Arrangement of Curriculum Thematic Teaching}

How to solve above questions? It is believed that thematic teaching method is an effective way, as it is proved by a dozen year of teaching experiences.

The modern and contemporary Chinese history was a long and complicated period within which many incidents happened, all kind of historic figures showed up, various partisans and politicians came to power successively. It was difficult to touch upon this big chuck of teaching contents. So, the tenet and outline of the course is very crucial. In teaching process, not only the theoretical education is emphasized, but also the highlights of the major contents should be explained fully. It was to center on "one topic", "two acknowledgements" and "three choices". The important historical events should be expounded in detail since they could reflect the time background and history facts and attracted the attentions of the students so that students would feel illuminated and inspired. Therefore, the basic framework of the course was formed by realizing the system transformation from textbook to the teaching. After many years of teaching experiences, the teaching content and target of "Outline of Modern Chinese History" course was formally well written. There were three review parts and ten chapters in the current "Outline of Modern Chinese History" course. The outlines was as followed:

Chapter I: Introduction. It was the beginning part. It told the basic issues in the modern Chinese history course with the purpose of letting the students know the course target, content and value of the textbook.

Chapter II: The Basic and Fundamental Reality of Modern Chinese History.

It focused on the modern Chinese political, economic, cultural, social situations, international environments in modern China. The modern social transformations, economic change, culture education, and scientific progression in modern China went with the complicated incidents and historical events. The complicated social situations caused many subsequent happenings in modern China.

Chapter III: Chinese Anti-aggressions and National Independence.

In this chapter, opium war, the Sino-Japanese war, National anti-Japanese war etc. were the focus of the main content. In the hundred and ten years from 1840 to 1949, foreign capitalist and imperialist invasions left the deep marks in Chinese history and society and inspired national awareness and patriotism of Chinese people. So, national patriotism was the cohesion power for Chinese people and spiritual support for self-discipline of the nation.

Chapter IV: The Exploration of the Chinese Historical Development tried by various modern classes and social Stratum.

Taiping movement led by the peasants, constitutional monarchy set up by reformist and progressive pioneers in modern china, democratic republic built by Sun Yet sun, "the Third Path" failure tried by China Democratic League, and Chinese Communist Party's role in modern Chinese history...., it verified an undeniable truth that socialism led by Chinese communist party was the only right and historic choice after New Democratic Revolution.

Chapter V: The Ascent of Modern Chinese Cultural Thought is Chinese Marxism---Sinicizing Marxism.

Through the social influence of many thoughts, ideological trends, schools of thoughts in modern Chinese history, it was very noticeable that Marxism and Mao Zedong's thoughts were the inevitability right way in Chinese history.

Chapter VI: Many Modern Chinese parties and the Historic Position of Chinese Communist Party.

Compare with many modern Chinese parties, such as Tung Meng Hui (Chinese Revolution League); the Kuoming tang (KMT), third party, China Democratic league, Chinese communist party was organized on the basis of democratic centralism and the major ruling pioneer party led by the working class. It gave full expression to democracy with full powers entrusted by people. Without Chinese communist party, there would be no new China. It was the Chinese Communist party, the only ruling party that could save China and Chinese 
people.

Chapter VII: Efforts made by many political and social powers and organizations on the way of Chinese modernization.

Though there were many reformations and revolutions on Chinese way to modernization, they all ended up in failures. Yang Wu Movement initiated by Li Hongzhang, the Revolution of 1911 led by Sun Yatsen, many other movements proved a truth that only change of productive forces and productive relations could China be survived. Socialism as a scientific socialism, it could develop China and pursue a more egalitarianism and boost economic growth.

Chapter VIII: The founding of Socialist System in China.

This chapter addressed the consolidation of Chinese People's democratic power at the beginning stage of founding the People's Republic of China and the recovery of the national economy, which paved way for socialism after New Democratic Revolution. The new China, the initial stage of socialism, was followed by The Three Great Movements. It was the necessary shift from the new Democratic Revolution to socialism. The New Democratic Revolution paved the way for the industrial proletarian class to emerge as the majority class in society. After which it then overthrew the capitalism and began constructing socialism. It also mentioned that the reforming the private ownership for capitals was very important part for socialist public economy and system. The total overhaul of the land ownership system, distribution of the capitals, and the centrally controlled public economy were the foundations for the socialist transformations.

Chapter IX: Arduous Explorations on Socialist Construction by Chinese Communist Party. It mainly discussed that Chinese Communist Party made various efforts on socialist construction during twenty years from 1956 to 1976. Land reform, public ownership, Great leap Forward, Cultural Revolution, etc. aimed to rapidly transformed China's economy from agrarian to industrial nation. There were many lessons and significance in those attempts.

Chapter X. The Opening and Reforming Policy and the Soaring of China.

Chapter XI. Socialism with Chinese characteristics has entered a new era.

It narrated the basic course of Chinese opening and Reforming policy, great achievements had been made in thirty years after reforming policy. The process of new policies was from reform of the economic structure to structures in all aspect, from internal vitalization to external opening up, and from cultural to many aspects of life. It was the great construction to realize Chinese modernization and strong country. China had made enormous achievements in economic, political, cultural and social construction. The reforming and opening-up policy was the practical combination of Marxism and Chinese peculiar reality and factual situation, the timely innovation of the socialist theory, as it was called the theory of "building socialism with Chinese characteristics".

In all, the application of the thematic teaching method to the "Outline of Modern Chinese History" course played very significant role in the teaching process. The current "Outline of Modern Chinese History” course had many contents and complicated plots which was hard to put evenly ink on every details and give squarely emphasis in the class. So, the lecturers must focus on the important parts with intensive explanations while at the same time let the students have a general picture of the whole structure in modern Chinese history. The application of the thematic teaching method to the classroom by centering on the textbook showed the efficient timeliness of the political and theoretic educational class. Take capital imperialism as an example, the aggressions of the imperialist countries with internal feudal system, it caused the backwardness and poverty of the modern China. The Teaching plan may change as the semester progresses based on the needs of the class. The key content, difficult part, and some doubts should be emphasized in the class so that the students could better receive the education effect. A systematic process in this course plan would help the students effectively reach the desired instructional goals. 


\section{Methods to Improve the Teaching Effect}

Of course, during the teaching practices, how to do well in the thematic teaching and realize the transformations from teaching content in the textbook system to the syllabus system required the professors fully function their subjective initiative and explore many various new ways in the teaching methods and mediums. It was believed that the following efforts should be made upon many years of teaching experiences.

Firstly, use the historical comparison method to improve the students' understanding ability. This historical comparison method is relatively a good teaching method as far as we know. It studies the development of the history by performing a feature-by-feature compassion of the two histories. This method benefits the teaching process in two successful ways. On the one hand, it caters the teaching to the needs of the contemporary college students. The current college students have strong crave for knowledge with active thinking and questing for the truth even though they lack of social experiences. They are good at using the brain though their worldviews are not fully developed naturally. A comparative approach was adopted to the teaching in a chronological and vertical way, relating many themes to development at different time of history, which benefits the students to have the right panorama of the whole history view, history truth and rule. With the right understanding of the modern Chinese history, it will naturally clear away the doubts and wrong misconception in the problem-analysis and problem-solving ability and judging ability to tell the right from the wrong. In all, the historical comparison method is conducive to their thoughts and mental health. On the other hand, comparising different historical issues at different time can contribute the students to develop the comparative analysis, antithesis objective mind and right conception to see through the historical events. It will make the class teaching easier, the contents memorable, and stimulate the students' learning enthusiasm. At the same time, it will enlarge the students study interests, and academic views based upon reliable and stable knowledge.

Furthermore, the "Outline of Modern Chinese History" course, as the important component part in theoretical and political course in college, targets to narrate history in the teaching process, educate the students through history window. In the process of applying the historical comparisons method to the teaching, the nihilisticism should be criticized. Thus, the students could have the objective and clear mind on the relationships of the national independence, People's liberation, and the country's prosperity and richness; on the relationship of the national revolution and democratic revolution; on the relationship between reformation and revolution, on the transforming the productive forces and productive relations, and the relationships between the national salvation and development. In discussing the key historical events, historic figures and important issues, the professors should guide the students to have a good command of nationality, democracy, class status, scienficalness, and timeliness. Only through those mentioned above, the students can better understand the country's history and situation, recognize the historical development rule in modern Chinese history through the Marxist viewpoint, methods and conception. Thus, the students naturally sense that Maxims, Chinese Communist Party, and socialism is the historical necessity and inevitability in the development of Chinese modern history.

Secondly, use multimedia PowerPoint in the classroom. PPT teaching makes the class more effective, flexible and much more dynamic so that it improves the teaching efficiency. Contemporary education theory believes that the college youths are more inclined to accept multimedia teaching mode since it is an advanced and more interesting medium with more attraction the energetic young students. PPT is becoming more and more widely in the field of education, which causes a very great impact and influence to the traditional teaching model since it can broadcast video and visual sound by stimulating the hearing and vision senses of the learners and assist traditional teaching by satisfying and pleasing the audiences. In this way, it effectively intensifies the teaching effect. Meanwhile multimedia PPT presents a lot more texts compared with traditional writing on the blackboard and shows a clear and 
coherent class teaching mode. It synchronized the teaching speed with the students' taken-in in the classroom and make sure to state enough amount of information in a limited teaching time.

Besides, multimedia PowerPoint could do with hand in hand with the "Outline of Modern Chinese History" course. The series of historical documents, such as "Centuries of China" "The Road of Revival", etc. are good complementary documents to show the students in the class. So consequently, the students would have a direct and vivid impression of the modern history through the watching of the videos. Furthermore, some films like "The Opium War", "The Burning of the Yuan Ming Yuan" "Sino-Japanese War" "Tokyo Trial” "Read River Valley" and so on, shot the Chinese modern history as their time background, themed as the Chinese patriotism and nationalism, benefited the student to know the historic events and historic figures better. In a word, multimedia teaching method promotes teaching efficiency in an active and vivid mode by arousing the students' initiative and achieving unexpected effect. Off course, as it should be, professors or lectures are still the main teaching subject with undeniable position who are the key and crucial force in teaching.

As a saying goes "Teaching has its method, and it is not fixed yet. No matter what kind of teaching methods, it can not be divorced from a certain teaching principle”. Any kind of certain teaching method couldn't fit all people. Therefore, the professors should continuously study and make a lot of efforts on exploration of good and new method during the teaching process so that we could innovate and develop the teaching style and stand at the advanced position in the academic research filed. Only in this way, could the "Outline of Modern Chinese History” course be effectively and better taught.

\section{References}

[1] Liang Xingliang and Yang Hong: teaching design of the outline of modern Chinese history, Shaanxi people's publishing house, 2016 Edition.

[2] Wang Jiugao: an analysis of the teaching model of the teaching group ---- "the outline of modern history of China" -- Taking the Peking University as an example, the guide of Ideological and theoretical education, the third term, 2009.

[3] Li Changguo: practice and exploration of special topic teaching in the outline of modern and contemporary history of China, Southwest University of Science and Technology,Higher Education Research, the second term of 2009.

[4] Li Xueping: "the application of multidimensional interaction thematic teaching method in Ideological and political teaching", Teaching and Management, the sixth term of 2009.

[5] Yan Zhicai: Reflections on the teaching content system of the outline of modern Chinese history, The Guide to Ideological and Theoretical Education, the ninth term of 2010. 